\title{
The morphology of the right ventricular outflow tract after percutaneous pulmonary valvotomy: long term follow up
}

\author{
$M$ ROBERTSON, $\dagger$ L N BENSON, $\dagger$ J S SMALLHORN, $\dagger$ N MUSEWE, $\dagger$ \\ R M FREEDOM, $\dagger$ C A F MOES, $\ddagger$ P BURROWS, $\ddagger$ A E JOHNSTON, * \\ F A BURROWS, * R D ROWE $\dagger$
}

From the Department of Paediatrics, Division of Cardiology, Variety Club Cardiac Catheterization Laboratories, $\dagger$ and Departments of Radiology $\ddagger$ and Anaesthesia, „ Hospital for Sick Children, Toronto, Ontario, Canada

SUMMARY Twenty nine patients (19 male, mean (SD) age 6.25 (0.5) years (range 0.16-15 years))with typical pulmonary valve stenosis were treated by balloon dilatation of the pulmonary valve. They were studied by echocardiography before the procedure, immediately after it, and at follow up (mean (SD) $10.2(5 \cdot 6)$ months, $n=18$ ). The morphology of the pulmonary valve, the right ventricular-pulmonary artery gradient, and ratio of the systolic to diastolic endocardial dimensions (infundibular ratio) were examined. No patient had pulmonary regurgitation before the study. The valve gradient was significantly reduced (47\%) from a mean (SD) of 72 (31) to 37 (23) $\mathrm{mm} \mathrm{Hg}$ with no short term change in cardiac index after dilatation with a balloon with a mean (SD) diameter that was $118(10 \cdot 8) \%$ of the valve annulus. The infundibular ratio was unchanged by the procedure $(0.49(0 \cdot 11)(n=21)$ before dilatation and $0.47(0.14)(n=16)$ after dilatation). In twenty seven patients the commissure of the pulmonary valve was seen to be torn after dilatation. Two patients with bicuspid valves had flail leaflets. Doppler examination at follow up showed mild pulmonary insufficiency in all 29 patients; the mean (SD) valve gradient $(31( \pm 21)$ $\mathrm{mm} \mathrm{Hg}$ ) at follow up was no different from the gradient found immediately after the procedure and infundibular ratio $(0.58(0.15)$ was not abnormal.

These data indicate that commissural tears are the primary mechanism of valve disruption and demonstrate that the dynamic right ventricular outflow tract obstruction relaxes and gradient reduction persists at follow up.

Percutaneous pulmonary valvotomy was first described by Rubio and Limon-Lason in 1954. They used a wire loop technique, ${ }^{12}$ but recently Semb et $a l$ and Kan $e t$ al have used balloon tipped catheters ${ }^{34}$ for the procedure, which has become established as a non-surgical treatment for congenital pulmonary valve stenosis. ${ }^{5-8}$ Some patients, however, have haemodynamically important obstruction of the

Requests for reprints to Dr L N Benson, Division of Cardiology, The Hospital for Sick Children, 555 University Avenue, Toronto, Ontario, Canada M5G 1 X8.

Accepted for publication 31 March 1987 right ventricular outflow tract after valvotomy ${ }^{5-8}$ despite what appears to be a tear in the pulmonary valve. ${ }^{9}$ We have studied this obstruction in patients after percutaneous pulmonary valvotomy.

\section{Patients and methods}

Over a 28 month period from January 1984, 38 percutaneous pulmonary valvotomies were performed for isolated pulmonary valve stenosis in 36 patients (19 boys; mean (SD) age $6.25(0.5)$ years). Seven patients had clinical and echocardiographic evidence of dysplasia of the pulmonary valve and were excluded from the analysis. ${ }^{10}$ All patients had clin- 

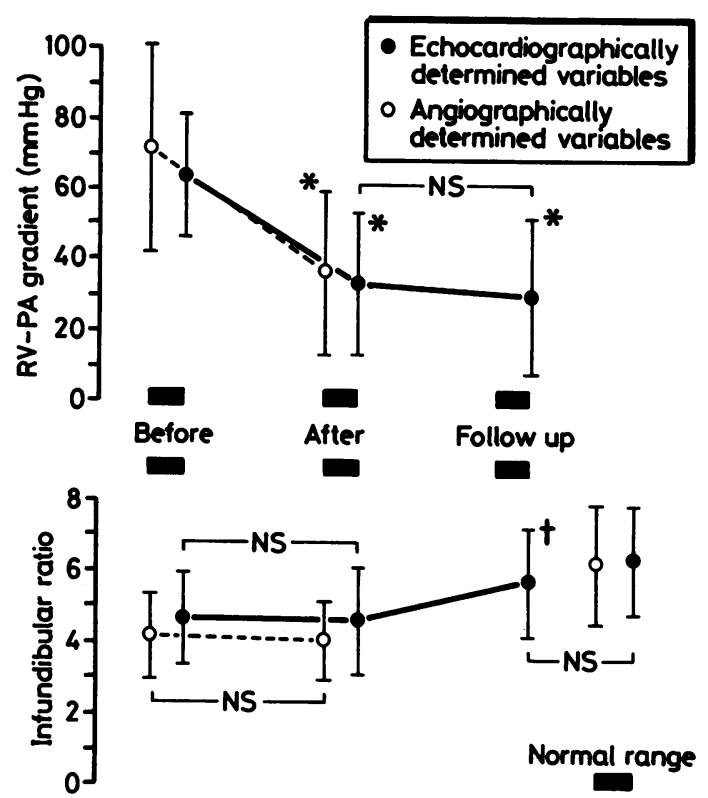

Fig 1 Right ventricular to pulmonary artery (RV-PA) gradient and infundibular ratio before, immediately after, and at follow up after balloon dilatation. ${ }^{*} p<0.001$ compared with values before valvotomy; $\dagger p<0.02$ for comparison of values immediately after valvotomy with values at follow up.

ical evidence of moderate to severe pulmonary valve stenosis $^{11}$ (fig 1). Informed consent was obtained from all parents as outlined and approved by the Human Subjects Protection Committee of the Faculty of Medicine, The Hospital for Sick Children, and University of Toronto.

Cross sectional echocardiography and Doppler echocardiography were performed in all patients before the procedure and within 24 hours of valvotomy. We used $3 \cdot 0,5 \cdot 0$, or $7 \cdot 5 \mathrm{MHz}$ mechanical sector scanners on either an ATL 600 , Ultramark 8 (Advanced Technology Laboratories Inc., Bellevue, WA), or Hewlett-Packard (Model 77020A) ultrasound imaging systems fitted with pulsed or continuous wave Doppler probes. Standard and high parasternal short axis views were routinely used to image the pulmonary valve, annulus, and infundibulum. ${ }^{9}$ Pulmonary annulus diameters measured at the hinge points of the pulmonary valve annulus were obtained from echocardiographic images (short axis view) and compared with the lateral projection from the right ventriculogram obtained before valvotomy. Doppler estimates of pulmonary valve gradients were obtained by use of the Bernoulli relation. ${ }^{12}$ Doppler estimated right ventricular outflow tract gradients in our laboratory were compared with simultaneous intracardiac pres- sures (right ventricle-pulmonary artery). This gave a correlation of $r=0.95 ; R V-P A$ gradient (cath) $=\stackrel{9}{+}$ $0.89 \mathrm{RV}-\mathrm{PA}$ gradient (Doppler) + 3.98; $\mathrm{SEE}=8.5$, $\mathrm{n}=29$.

Cardiac catheterisation was performed under ketamine anaesthesia given by continuous infusion. ${ }^{13}$ The details of the dilatation procedure in used in our laboratories have been outlined else- $\vec{O}$ where. ${ }^{14}$ Briefly, two venous catheters ( 7 French) were manoeuvred into the right ventricle and main pulmonary artery for simultaneous gradient measurements, and a femoral artery line ( 5 French) was placed to monitor systemic pressure. Cardiac output in was measured by a Fick determination (measured $\omega$ oxygen consumption), thermodilution, or dye curve, $\omega_{\omega}^{N}$ and a biplane right ventricular axial angiogram (one $\mathscr{C}$ plane always true lateral) was performed. A Teflon coated exchange guide wire was positioned, preferably in the distal left pulmonary artery, and a balloon tipped $3 \mathrm{~cm}$ long 8 or 9 French valvotomy catheter (Mansfield Scientific, Waterstown, MA) was passed over it and across the pulmonary valve annulus. The approximate location of the valve was determined from the lateral right ventriculogram and marked by a radio-opaque marker taped to the lateral chest wall. We selected balloon catheters that were approximately $120 \%$ of the diameter of the pulmonary valve annulus measured on the lateral right ventriculogram and corrected for magnification against the angiocatheter diameter. Several balloon inflation/ deflation cycles (average 4) lasting approximately 15-20 seconds each were performed until no discernible waist (caused by the stenotic pulmonary valve leaflets) was seen during fluoroscopy. Inflation pressures were initially measured by an in-line manometer to the rated manufacturer's tolerance (3-4 atm) $(30.32-40.43 \mathrm{kPa})$ but this was abandoned in the later 25 patients because maximal intraballoon pressures were rarely achieved. ${ }^{7}$ Right ventricular and femoral artery pressures were monitored throughout the dilatation procedure. Right ventricularpulmonary artery pressures were measured immediately upon withdrawal of the balloon catheter and were observed for 15 to 20 minutes before cardiac output measurements and biplane right ventricular axial angiography were repeated.

From a replay of the right ventriculogram we N determined whether the right ventricular outflow 0 tract showed dynamic or fixed obstruction. $A \underset{c}{2}$ dynamic obstruction was measured in terms of the infundibular ratio. This was calculated as the ratio of $\cong$ the systolic and diastolic endocardial dimensions 0 measured at a point equidistant from the pulmonary $\overrightarrow{0}$ and tricuspid valves. Ten normal right ventricular $\stackrel{\mathbb{D}}{\Omega}$ angiograms were similarly measured and found to $\mathbb{\nabla}$ have a mean $(\mathrm{SD})$ ratio of $0.64(0 \cdot 16)$. Additionally, 
an echocardiographically determined infundibular ratio was measured before cardiac catheterisation from the short axis view at the base of the heart between pulmonary and tricuspid valves at end systole and diastole. The infundibular ratio in 10 patients with normal cardiac anatomy was 0.63 $(0 \cdot 16)$. Angiograms complicated by extrasystoles or echocardiograms of poor resolution were not used in data analysis.

Two patients required a second intracardiac study and valvotomy at 9 and 16 months because haemodynamically important right ventricular outflow tract obstruction recurred. Two other patients needed subsequent surgical repair because of fixed fibromuscular and subpulmonary obstruction and both required an outflow tract patch; one of these patients has been reported in detail elsewhere. ${ }^{9} \mathrm{~A}$ third patient with fixed obstruction is awaiting surgical repair. One patient had undergone a surgical pulmonary valvotomy three months before balloon dilatation of the valve.

\section{STATISTICAL ANALYSIS}

Data are presented as mean (1 SD). Statistical significance was determined by the two tailed $t$ test for paired data. Individual patient data are available from the authors upon request.

\section{Results}

ECHOCARDIOGRAPHIC DATA BEFORE BALLOON DILATATION

In all but two patients commissural fusion of a tricuspid pulmonary valve was identified as the mechanism of stenosis ${ }^{15}$ (fig 1). Doppler study did not show evidence of pulmonary regurgitation in any patient. The echocardiogram predicted the angiographic pulmonary annulus as: angiographic annulus $(\mathrm{mm})=1.04$ (echographic annulus $(\mathrm{mm}))-1.03 ; \mathrm{r}=0.87 ; \mathrm{SEE}=1.1 ; \mathrm{n}=20$. The mean (SD) pulmonary valve gradient in the unsedated resting patients before catheterisation was $66 \cdot 1(16 \cdot 7)$ (range 39 to $100 \mathrm{~mm} \mathrm{Hg}$ ).

\section{RESULTS IMMEDIATELY BEFORE AND}

\section{IMMEDIATELY AFTER VALVOTOMY}

The mean (1 SD) pulmonary valve annulus was $14 \cdot 7$ ( $3.3 \mathrm{~mm}$ ) (range 8 to $20 \mathrm{~mm}$ ) by angiography. The average right ventricular-pulmonary artery gradient fell by $47 \%$ at catheterisation from 72 (31) $\mathrm{mm} \mathrm{Hg}$ (range 34-172 $\mathrm{mm} \mathrm{Hg}$ ) to 37 (23) $\mathrm{mm} \mathrm{Hg}$ (range 5 to $114 \mathrm{~mm} \mathrm{Hg})(\mathrm{p}<0.001)$ (fig 1). Similarly, the ratio of right ventricular pressure to systemic arterial pressure fell by $59 \%$ from $0.85(0.26) \%$ (range 0.47 to $1.51 \%$ ) to $0.50(0.25) \%$ (range 0.16 to $1.30 \%$ ). The pulmonary valves were dilated with balloons that were on average $17.5(3.4) \mathrm{mm}$ in diameter and $118(10.8) \%$ of the annulus size. There was no change in the angiographically measured size of the annulus after dilatation. Mean cardiac index was $3.98(1.06) \mathrm{l} / \mathrm{min} / \mathrm{m}^{2}$ and there was no significant change after dilatation (4.29 $(1.21) \mathrm{l} / \mathrm{min} / \mathrm{m}^{2}$, $n=12$ ). The infundibular ratio was measured by angiography $(0.42(0.11), \mathrm{n}=30)$ and echocardiography $(0.49(0.11), \mathrm{n}=21)$ before dilatation. There was no significant difference in either $(0.41$ $(0.1), \mathrm{n}=30$; and $0.47(0.14), \mathrm{n}=16$ respectively) after dilatation. After catheterisation, when the child was unsedated and resting, the echocardiographic pulmonary valve gradient was $53 \%$ lower (34 (18) $\mathrm{mm} \mathrm{Hg}$ ) (range 8 to $80, \mathrm{n}=27$ ) than before the procedure $(p<0.001)$ (fig 1$)$.

In all patients there was a dynamic infundibular component to the right ventricular obstruction as shown by the replay of the lateral right ventricular angiogram, and in three patients there was a fixed obstructive element. We identified commissural tears in all patients who had trileaflet valves shown by cross sectional echocardiography. Tears were seen in one or two commissures and occasionally extended to the margin of the valve annulus (fig 2). In the two patients with bicuspid valves the valve leaflet tissue was ruptured and in both there was a non-competent flailed valve.

\section{LONG TERM FOLLOW UP}

Echocardiographic images of the right ventricular outflow tract and pulmonary valve and Doppler estimates of the pulmonary valve gradients were obtained at follow up in 18 patients, $10 \cdot 2$ (5.6) (range 4 to 24) months after the initial procedure. The average valve gradient was $(31$ (21) $\mathrm{mm} \mathrm{Hg}$ ) not significantly different from the value immediately after dilatation. Additionally the echocardiographically derived infundibular ratio ( 0.5 $(0 \cdot 15)$ ) was not significantly different from the normal values (fig 1). All but four patients had Doppler evidence of pulmonary insufficiency of mild degree; no patients showed progression of the insufficiency either by Doppler study or by clinical evaluation.

At the end of the procedure nine $(31 \%)$ of 29 patients had right ventricular pressures that were $>50 \%$ of systolic or a gradient of $>35 \mathrm{~mm} \mathrm{Hg}$. In three of these subpulmonary obstruction established by echocardiography and angiography was unchanged at follow up, suggesting a fixed component. In four patients there had been a further reduction in valve gradient to $24(6 \cdot 6) \mathrm{mm} \mathrm{Hg}$ and an increase in infundibular ratio from $0.39(0.18)$ to 0.54 $(0.16)(p<0.0001)$. In one patient the valve gradient was unchanged ( $36 \mathrm{~mm} \mathrm{Hg}$ ); another has not yet been seen at follow up. 

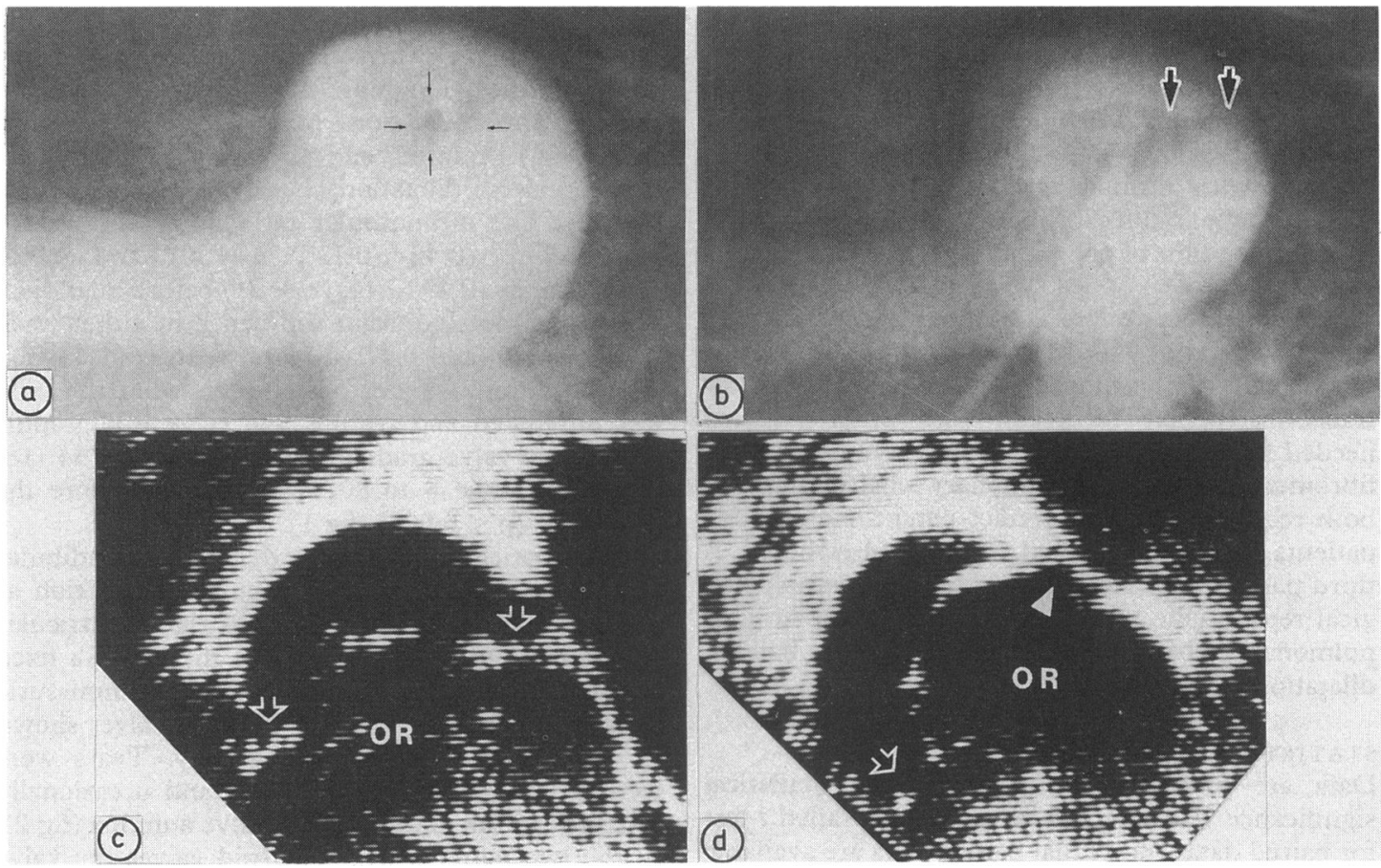

Fig 2 Pulmonary artery angiograms: (a) before dilatation (cranial-caudal view) showing outlining of the haemodynamic orifice with non-opacified blood (arrows); (b) after dilatation showing a linear tear to the annulus margin (arrows) outlined by non-opacified blood. (c) Short axis, high parasternal echocardiogram before dilatation showing tricuspid valve and two of the fused commissures at 3 and 7 'clock (arrows). (d) Echocardiogram after dilatation showing the split (solid arrow). The other commissure at 7 o'clock remains fused. OR, orifice

Two patients had a second valvotomy with balloons that were $115 \%$ of the valve ring diameter. In one the gradient fell from 54 to $18 \mathrm{~mm} \mathrm{Hg}$ and this fall was maintained at six month follow up. In the second child, however, the gradient at follow up was unchanged $(81 \mathrm{~mm} \mathrm{Hg})$ and there was angiographic and echocardiographic evidence of subvalvar obstruction that did not resolve over a 12 month period. This child had surgical repair with an infundibular patch and surgical valvotomy. The valve leaflets were bicuspid and markedly thickened with a $9 \mathrm{~mm}$ orifice and fused commissures. There was no evidence of valve disruption caused by balloon dilatation.

\section{Discussion}

Balloon dilatation of the pulmonary valve was reported to be a safe and effective means of reducing the right ventricular to pulmonary artery gradient in typical pulmonary valve stenosis. ${ }^{4-8}$ Our experience with this technique further supports these initial observations. The mechanism of stenosis in this set- ting appears to be varying degrees of commissural fusion on a trileaflet valve with minimal or no thickening of valve leaflets. ${ }^{15}$ Echocardiographic data and the appearance at operation show that in most cases the reduction in gradient was apparently achieved by splitting of adherent commissural elements (fig 2). ${ }^{8916}$ Pulmonary valve insufficiency that is demonstrable by echocardiography and Doppler examination is an inevitable consequence of an effective dilatation. Insufficiency is occasionally audible by auscultation, ${ }^{91718}$ suggesting damage to the leaflet-supporting apparatus. It is not clear, how- $\sigma$ ever, why pulmonary insufficiency is a component of $N$ an effective dilatation. Commissural tearing was N never seen to be uniform in all three margins and sometimes extended to the limits of the valve annulus. Thus loss of support at the commissural marginal tear may account for the insufficiency.

Paracommissural tears along leaflet tissue could also produce echocardiographic findings that are indistinguishable from those produced by commissural splitting. ${ }^{7}$ Annular measurements after balloon valvotomy discount the notion that ring dilatation 
(by overlarge balloons) may contribute to this finding. At follow up most patients continued to have valve insufficiency; this was mild and did not increase to become a clinical problem. These incomplete tears probably also account for the residual gradients seen after dilatation. The asymmetry of the tears may also account for the improved results in gradient reduction seen when balloons that have larger diameters than the valve annulus are used. ${ }^{419}$

Angiographic examination after dilatation in most patients demonstrated improved valve leaflet mobility of only a single leaflet, with the continued presence of a "contrast jet", albeit wider than before the procedure, and doming of the adjacent leaflets implying persistence of fusion of the valve commissures (P Burrows, personal communication). Two of our patients had bicuspid valves and in these patients balloon valvotomy resulted in flail, non-supported valve mechanisms and regurgitation as previously reported by Lababidi and Wu. ${ }^{5}$ We can only speculate about the reasons for this finding. There may be an intrinsic abnormality in the valve-annulus attachments or perhaps a bicuspid valve is more vulnerable to stress, because the area of the valve leaflet is larger. Alternatively, the action of the heart on the balloon may result in a shearing motion that disrupts the valve attachments to the ring. All these elements could be operating to varying degrees.

The data from our series suggest that a dynamic obstruction of the subpulmonary outflow tract is a frequent component of pulmonary valve stenosis. This may persist after the procedure ${ }^{717}$ but if valve dilatation is successful it can be expected to regress ${ }^{18}$ with a further reduction in gradient. This observation is supported by previous studies after surgical valvotomy. ${ }^{19-21}$ Unlike Ben-Shacher et al we did not find that dynamic obstruction of the outflow tract became worse after the procedure, ${ }^{16}$ despite the fact that before dilatation 11 of our patients had right ventricular pressures $>85 \%$ systemic; in five right ventricular pressure was greater than systemic pressure. It may be that our results were influenced by the use of continuous ketamine anaesthesia rather than sedation during the procedure. A reduction of sympathetic outflow could have moderated the effect of the hypercontractile outflow tract.

When the residual gradient is $>35 \mathrm{~mm} \mathrm{Hg}$ or $50 \%$ systemic right ventricular pressures we use cross sectional echocardiography to visualise the morphology of the valve (to assess whether a leaflet tear has occurred) and we carefully examine the right ventriculogram obtained after balloon valvotomy, paying particular attention to the mobility of the valve leaflets. We do not perform further dilatations with larger balloons if the above studies suggest that the commissural tear is adequate. In such circum- stances it is likely that the gradient will be further reduced as infundibular hypertrophy regresses.

\section{References}

1 Rubio Y, Limon-Lason R. Treatment of pulmonary valvular stenosis and of tricuspid stenosis using a modified catheter. Proceedings of the 2nd World Congress of Cardiology, Washington DC, September 1954, page 205.

2 Rashkind WJ. Interventional cardiac catheterization in congenital heart disease. Int J Cardiol 1985;7:7-11.

3 Semb BKH, Tjonneland D, Stake G, Aabyholm G. "Balloon valvulotomy" of congenital pulmonary valve stenosis with tricuspid valve insufficiency. Cardiovasc Radiol 1979;2:239-41.

4 Kan JS, White RI Jr, Mitchell SE, Gardner TJ. Percutaneous balloon valvuloplasty: a new method for treating congenital pulmonary valve stenosis. $N \mathrm{Engl}$ $J$ Med 1982;307;540-2.

5 Lababidi Z, Wu J-R. Percutaneous balloon pulmonary valvuloplasty. Am J Cardiol 1983;52:560-2.

6 Kan JS, White RI Jr, Mitchell SE, Anderson JH, Gardner TJ. Percutaneous transluminal balloon valvuloplasty for pulmonary valve stenosis. Circulation 1984;69:554-60.

7 Rocchini AP, Kveselis DA, Crowley D, Dick M, Rosenthal A. Percutaneous balloon valvuloplasty for treatment of congenital pulmonary valvular stenosis in children. J Am Coll Cardiol 1984;3:1005-12.

8 Tynan M, Baker EJ, Rohmer J. Percutaneous balloon pulmonary valvuloplasty. Br Heart J 1985;53:520-4.

9 Benson LN, Smallhorn J, Freedom RM, Trusler GA, Rowe RD. Pulmonary valve morphology after balloon dilation of pulmonary valve stenosis. Cathet Cardiovasc Diagn 1985;11:161-6.

10 Musewe NN, Robertson MA, Benson LN, et al. The dysplastic pulmonary valve: echocardiographic features and results of balloon dilatation. Br Heart $J$ 1987;57:364-70.

11 Rowe RD. Pulmonary stenosis with normal aortic root. In: Keith JD, Rowe RD, Vlad P, eds. Heart diseases in infancy and childhood. New York: MacMillan, 1978: 761 .

12 Hatle L, Anglesen B. Doppler ultrasound in cardiology. Philadelphia: Lea and Febiger, 1969: 8-73.

13 Shulman D, Beardsmore CS, Aronson HB, Godfrey S. The effects of ketamine on the functional residual capacity in young children. Anesthesiology 1985;62:551-6.

14 Freedom RM, Smallhorn JF, Benson LN. Evaluation of severity of pulmonary stenosis and results of pulmonary valve balloon angioplasty in children. Proceedings from St. Christopher's Symposium in Management of Congenital Valve Disease (in press), 1987.

15 Jeffrey RF, Moller JH, Amplatz K. The dysplastic pulmonary valve: a new roentgenographic entity. $A m J$ Roentgenol Radium Ther Nucl Med 1972;114:322-39.

16 Ben-Shachar G, Cohen MH, Sivakoff MC, Portman MA, Riemembschneider TA, Van Hee Keren DW. Development of infundibular obstruction after per- 
cutaneous pulmonary balloon valvuloplasty. J Am Coll Cardiol 1985;5:754-6.

17 Radtke W, Keane JF, Fellows KE, Lang P, Lock JE. Percutaneous balloon valvotomy of congenital pulmonary stenosis using oversized balloons. J Am Coll Cardiol 1986;8:909-15.

18 Kveselis DA, Rocchini AP, Snider R, Rosenthal A, Crowley DC, Dick $M$ II. Results of balloon valvuloplasty in the treatment of congenital valvular pulmonary stenosis in children. Am J Cardiol 1985;56:527-32.

19 Engel MA, Holswade GR, Goldberg HP, Lukas DS,
Glenn F. Regression after open valvotomy of infundibular stenosis accompanying severe valvular pulmonic stenosis. Circulation 1958;17:862-73.

20 Griffith BP, Hardesty, RL, Skewers RD, Lenberg DB, Ferson PF, Bahnson HT. Pulmonary valvotomy done for pulmonary stenosis: results in children with and without muscular infundibular hypertrophy. $J$ Thorac Cardiovasc Surg 1982;83:577-83.

21 Ring JC, Kulik TJ, Burke BA, Lock JE. Pathologic changes induced by dilatation of the pulmonary valve annulus with over-large balloons in normal newborn lambs. Am J Cardiol 1985;55:210-4. 